\title{
Indole derivatives inhibit hepatitis $C$ virus replication through induction of pro-inflammatory cytokines
}

\author{
S. LEE, G. JIN, D. KIM, S. SON, K. LEE*, C. LEE* \\ College of Pharmacy, Dongguk University-Seoul, 410-050, Goyang, Republic of Korea
}

Received September 4, 2014; accepted February 11, 2015

\begin{abstract}
Summary. - Previously, we discovered a series of indole derivatives as a new class of hepatitis $\mathrm{C}$ virus (HCV) replication inhibitors by using a target-free chemical genetic strategy. Through a structure-activity relationship study, the compound $12 \mathrm{e}$ was identified as the most potent inhibitor of this class $\left(\mathrm{EC}_{50}=1.1 \mu \mathrm{mol} / \mathrm{l}\right)$ with minimal cytotoxicity $\left(\mathrm{CC}_{50}=61.8 \mu \mathrm{mol} / \mathrm{l}\right)$. In order to gain insight into its detailed antiviral mechanism of action, we performed PCR array analyses and found that $12 \mathrm{e}$ was able to activate transcription of a number of proinflammatory as well as antiviral cytokine genes including CXCL-8, IL- $1 \alpha$, TNF- $\alpha$, IL-3, IRAK-1, and DDX58. Their induction by $12 \mathrm{e}$ was verified by individual RT-PCR analyses. In addition, 12e was found to stimulate secretion of soluble factors with anti-HCV replication activity. Among the 12e-induced pro-inflammatory cytokines, CXCL- 8 showed a strong positive correlation between its transcriptional activation and antiviral potency. Interestingly, a recombinant CXCL-8 protein also reduced HCV replication, though only moderately. In conclusion, we found a novel mode of action of indole derivatives in inhibiting HCV replication, particularly the induction of pro-inflammatory cytokines.
\end{abstract}

Keywords: hepatitis C virus; indole derivatives; replication inhibitors; CXCL-8; pro-inflammatory cytokines; transcriptional activation

\section{Introduction}

Hepatitis C virus (HCV) is a hepatotropic single-stranded RNA virus. It is responsible for chronic inflammatory liver diseases including liver cirrhosis and hepatocellular carcinoma. Around 170 million people are estimated to be active HCV-positive carriers worldwide (Shepard et al., 2005). Approximately $40 \sim 45 \%$ of all liver transplantations, which are performed in United States, are directly related to HCV infection (MukherjeeSorrell, 2008). Therefore, HCV-associated morbidity and mortality has been a severe burden on the

*Corresponding authors. E-mail: choongholee@dongguk.edu; kaylee@dongguk.edu; phone: +82 31961 5223; +82 319615214. Abbreviations: DAA = direct-acting antiviral; EMCV = encephalomyocarditis virus; GAPDH = glyceraldehyde 3-phosphate dehydrogenase; $\mathrm{HCV}=$ hepatitis $\mathrm{C}$ virus; IFN = interferon; IRES = internal ribosomal entry site health care system of many countries with a high incidence rate of $\mathrm{HCV}$ infection.

Combined treatment with pegylated interferon (IFN)- $a$ and ribavirin has served as standard of care for most of $\mathrm{HCV}$ patients (Wilby et al., 2012). However, undesirable side effects including flu-like symptoms, anemia, depression, and suicidal thoughts have been consistently associated with this IFN-based therapy. Thanks to recently approved directacting antivirals (DAAs) including NS3 protease inhibitors (Telaprevir and Boceprevir) and an NS5B polymerase inhibitor (Sofosbuvir), the current standard of care for $\mathrm{HCV}$-infected patients is starting to move toward a multiple combination regimen composed of one of these DAAs plus pegylated IFN- $\alpha$ and ribavirin (Lee, 2013a). In addition, a number of promising clinical results were revealed recently regarding a possibility of IFN-free combination treatment with only DAAs (Everson et al., 2014). However, in spite of their high efficacy and safety profiles, DAAs alone do not 
seem to play a major role in combination therapy for most $\mathrm{HCV}$ patients in the near future due to their relatively high price. Therefore, in order to develop a more affordable and effective regimen for treatment of $\mathrm{HCV}$ infection, a new class of anti-HCV therapeutics with a novel mechanism of action is still urgently needed.

For this purpose, we screened our in-house library comprising $\sim 6000$ compounds and identified compound $12 \mathrm{e}$ as the most potent inhibitor with minimal cytotoxicity $\left(\mathrm{EC}_{50}=1.1 \mu \mathrm{mol} / \mathrm{l}\right.$ and $\mathrm{CC}_{50}=61.8 \mu \mathrm{mol} / \mathrm{l}$ ) (Jin et al., 2014). However, its detailed antiviral mode of action was not clear. Here, we demonstrated that the anti-HCV activity of $12 \mathrm{e}$ depends on the induction of pro-inflammatory as well as antiviral cytokine genes at transcriptional level. Especially, the induction of CXCL-8 gene seems to play an important role in the suppression of HCV replication by $12 \mathrm{e}$.

\section{Materials and Methods}

Indole derivatives. All of the indole compounds including (E)-3-(1H-indol-3-yl)- $N$-isopropylacrylamide (2b), (E)-N-(3,4dimethoxybenzyl)-3-(1H-indol-3-yl)acrylamide (2c), (E)-N,Ndiethyl-3-(1H-indol-3-yl)acrylamide (2d), (E)-3-(1H-indol-3-yl)2-methyl-N-(4-(trifluoromethyl)phenyl)acrylamide (8), (E)-N-(2(dimethylamino)ethyl)-3-(1H-indol-3-yl)-2-methylacrylamide (10), (E)- $N$-(3-(1H-imidazol-1-yl)propyl)-3-(1H-indol-3-yl)-2methylacrylamide (11), (E)-N-(4-tert-butylphenyl)-3-(1H-indol-3 -yl)-2-methylacrylamide (12a), (E)-N-(4-tert-butylphenyl)-2-methyl-3-(5-methyl- $1 \mathrm{H}$-indol-3-yl)acrylamide (12c), (E)-N-(4-tertbutylphenyl)-3-(5-methoxy- $1 H$-indol-3-yl)-2-methylacrylamide (12d), (E)-N-(4-tert-butylphenyl)-3-(5-cyano-1H-indol-3-yl)-2methylacrylamide (12e), and (E)- $N$-(4-tert-butylphenyl)-2-methyl3-(6-methyl-1H-indol-3-yl)acrylamide (12g) were synthesized as described previously (Jin et al., 2014) (Table 2 and 3, Fig. 1a).

Cell culture. Huh7.5 cell line of the human hepatoma origin was cultured in monolayers as described previously (Blight et al., 2002; Sklan et al., 2007), in media consisting of DMEM (Sigma) supplemented with $1 \%$ L-glutamine (Hyclone), $1 \%$ penicillin, $1 \%$ streptomycin (Hyclone), and $10 \%$ FBS (JR Scientific).

Plasmids. Rluc-J6/JFH1 (FL-J6/JFH1-5'C19Rluc2AUbi) is a monocistronic, full-length $\mathrm{HCV}$ genome that expresses a renilla luciferase and was derived from the previously described infectious genotype 2a HCV genome J6/JFH1 (Lindenbach et al., 2005; Tscherne et al., 2006). Bart79I is a high-efficiency bicistronic subgenomic replicon of HCV derived from an HCV genotype $1 \mathrm{~b}$ Con 1 sequence that harbors the neomycin phosphotransferase gene in the first cistron and the HCV nonstructural proteins in the second cistron under the translational control of an EMCV IRES (Blight et al., 2002). This plasmid also has an adaptive mutation (S2204I) in NS5A, which increases replication efficiency. FL-J6/ JFH1, FL-J6/JFH1-5'C19Rluc2AUbi and Bart79I plasmids are gifts from Dr. Charles Rice at the Rockefeller University. An IL-8 promoter-luciferase reporter vector (pGL3-pIL-8) was obtained from Dr. J.-S. Chun in Gwangju Institute of Science and Technology (Korea) (Choi et al., 2006).

Production of HCV RNA by in vitro transcription. In vitro transcription to produce HCV RNA genomes was performed as previously described (Lee, 2013b). Briefly, WT Bart79I, J6/JFH1, or Rluc-J6/JFH1 plasmids were linearized by digestion with ScaI (Bart79I) or XbaI (J6/JFH1 and Rluc-J6/JFH1) (NEB). The T7 promoter-driven in vitro transcription was performed on the digested plasmid to produce the WT HCV RNA genomes using a MEGAscript kit (Ambion).

Generation of stable HCV replicon cell lines. The establishment of Huh7.5 cells stably maintaining a Bart79I subgenomic replicon in the presence of G418 selection was described elsewhere (Cho et al., 2010). Briefly, the in vitro-transcribed Bart79I RNA was transfected into Huh7.5 cells using the Lipofectamine 2000 transfection reagent (Invitrogen). The transfected cells were supplemented with G418 to the final concentration of $125 \mu \mathrm{g} / \mathrm{ml}$. This selection medium was replaced every 3 days for 3 weeks. The establishment of Huh7.5 cells stably maintaining a J6/JFH1 infectious clone was performed by transfecting the in vitro-transcribed J6/JFH1 RNA into Huh7.5 cells using the Lipofectamine 2000 transfection reagent. The establishment of Huh7.5 cells stably maintaining an Rluc-J6/ JFH1 clone was performed similarly.

Cytotoxicity and luciferase assays. $1.8 \times 10^{4}$ cells stably transfected with the HCV replicon were plated onto a white 96-well plate (Cos$\operatorname{tar} 3610$ ) and supplemented with DMSO or $1 \mathrm{nmol} / \mathrm{l}, 10 \mathrm{nmol} / \mathrm{l}$, $100 \mathrm{nmol} / \mathrm{l}, 1 \mu \mathrm{mol} / \mathrm{l}, 10 \mu \mathrm{mol} / \mathrm{l}$, and $100 \mu \mathrm{mol} / \mathrm{l}$, respectively, of designated compound for 3 days. Cells were incubated for $3 \mathrm{hr}$ at $37^{\circ} \mathrm{C}$ in the presence of EZ-CYTOX (10\% tetrazolium salt; Dogen) reagent to assess cytotoxicity of the compound. Simultaneously, renilla luciferase activities were measured using a luciferase reagent ( $1 \mathrm{mmol} / \mathrm{l}$ coelenerazine in Methanol-HCL, Goldbio).

Real-time RT-PCR. 3 X 105 Huh7.5-J6/JFH1 or Bart79I cells were plated onto a 6-well plate (Costar 3610) and supplemented with DMSO or designated compound with indicated concentrations. At 3 days after incubation, total cellular RNA was extracted using the RNeasy ${ }^{\circ}$ mini kit (Qiagen) in accordance with the manufacturer's instructions. The yield of extracted RNA was assessed spectrophotometrically. The expression of HCV and cellular RNA was measured by quantitative real-time reverse-transcription polymerase chain reaction (qRT-PCR) analysis as previously described (Jin et al., 2014). Each sample was normalized to the endogenous reference gene glyceraldehyde-3phosphate dehydrogenase (GAPDH). The cDNA quantification was performed by the CFX384 qRT-PCR detection system (Bio-Rad, US). The primers used in the qRT-PCR reactions were as follows: FW-J6/JFH1: 5'-CTCCGCCATGAATCACTC-3', RV-J6/JFH1 5'-ACGACACTCATACTAACGC-3', FW-Bart79I 5'-AGAGCCAT AGTGGTCT-3', RV-Bart79I5'-CCAAATCTCCAGGCATTGAGC-3', FW-GAPDH 5'-TGGTCTCCTCTGACTTCA-3', and RV-GAPDH 5'-CGTTGTCATACCAGGAAATG-3'. 7 sets of primers used for qRT-PCR analyses of following genes - CXCL-8, IL-1 $\alpha$, TNF- $\alpha$, IL-3, TLR-7, IRAK-1, and DDX-58 - were purchased from Qiagen. 
Table 1. Result of PCR array analyses of (A) cytokine and (B) antiviral genes induced by treatment with either 12e or IFN- $\alpha$ (Huh7.5-J6/JFH1 cells were treated with DMSO, $10 \mu \mathrm{mol} / \mathrm{l}$ of $12 \mathrm{e}$, or $10 \mathrm{pg} / \mathrm{ml}$ of IFN- $\alpha$ for 3 days. PCR array analyses were performed on isolated RNA using antiviral and cytokine PCR array kits)

A

\begin{tabular}{|c|c|c|c|c|c|}
\hline Gene & $\begin{array}{l}\text { Fold induction } \\
\text { by } 12 \mathrm{e}\end{array}$ & $\begin{array}{l}\text { Fold induction by } \\
\text { IFN- } \alpha\end{array}$ & Gene & $\begin{array}{l}\text { Fold induction } \\
\text { by } 12 \mathrm{e}\end{array}$ & $\begin{array}{l}\text { Fold induction by } \\
\text { IFN- } a\end{array}$ \\
\hline CXCL-8 & 6.67 & 1.47 & CCL-3 & 1.96 & 1.22 \\
\hline IL-1 $1 \alpha$ & 5.98 & 3.22 & CCL-8 & 1.96 & 1.22 \\
\hline TNF- $\alpha$ & 5.69 & 1.19 & CSF-2 & 1.96 & 1.22 \\
\hline IL-3 & 4.64 & 2.10 & CXCL-13 & 1.96 & 1.22 \\
\hline IL-15 & 4.49 & 2.13 & FASLG & 1.96 & 1.22 \\
\hline CSF-3 & 4.21 & 2.23 & IFN- $\alpha 2$ & 1.96 & 1.22 \\
\hline CXCL-12 & 4.18 & 0.70 & IFN- $\gamma$ & 1.96 & 1.22 \\
\hline IL-5 & 3.91 & 1.06 & IL- $12 \beta$ & 1.96 & 1.22 \\
\hline IL-7 & 3.88 & 1.92 & IL-17a & 1.96 & 1.22 \\
\hline MSTN & 3.85 & 1.50 & IL- $1 \beta$ & 1.96 & 1.22 \\
\hline SPP-1 & 3.81 & 1.80 & IL-2 & 1.96 & 1.22 \\
\hline CCL-20 & 3.55 & 1.32 & IL-4 & 1.96 & 1.66 \\
\hline IL-9 & 3.44 & 1.14 & IL-6 & 1.96 & 1.22 \\
\hline CSF-1 & 3.38 & 1.47 & OSM & 1.96 & 1.22 \\
\hline CXCL-2 & 3.38 & 1.53 & РPBP & 1.96 & 1.22 \\
\hline TGF- $\beta 2$ & 3.35 & 1.90 & CXCL-16 & 1.9 & 1.28 \\
\hline IL-24 & 3.21 & 1.45 & CCL-7 & 1.88 & 1.22 \\
\hline CXCL-5 & 3.09 & 1.37 & IL-27 & 1.87 & 1.43 \\
\hline CCL-17 & 2.76 & 1.23 & TNFSF-11 & 1.83 & 1.03 \\
\hline CXCL-1 & 2.71 & 1.43 & IL-13 & 1.71 & 1.35 \\
\hline CCL-19 & 2.68 & 1.91 & XCL-1 & 1.65 & 1.50 \\
\hline CNTF & 2.61 & 1.47 & MIF & 1.63 & 1.26 \\
\hline BMP-6 & 2.47 & 1.22 & BMP-2 & 1.6 & 1.27 \\
\hline CCL-5 & 2.46 & 3.37 & BMP-4 & 1.59 & 1.17 \\
\hline CXCL-10 & 2.41 & 1.37 & CX3CL-1 & 1.58 & 1.34 \\
\hline LTB & 2.34 & 0.96 & LTA & 1.58 & 1.20 \\
\hline IL-18 & 2.08 & 1.23 & LIF & 1.55 & 1.14 \\
\hline IL-12a & 2.07 & 1.13 & IL-10 & 1.52 & 0.95 \\
\hline IL-22 & 2.02 & 1.71 & VEGF- $\alpha$ & 1.48 & 1.28 \\
\hline IL23a & 2.02 & 1.69 & RPLP0 & 1.29 & 0.95 \\
\hline IL17F & 2.00 & 2.54 & $\mathrm{CD} 40 \mathrm{~L} \gamma$ & 1.26 & 0.74 \\
\hline TNFSF13 $\beta$ & 2.00 & 1.22 & IL-16 & 1.18 & 0.68 \\
\hline CXCL9 & 1.99 & 1.41 & CCL-13 & 1.16 & 1.37 \\
\hline TNFRSF $11 \beta$ & 1.99 & 1.40 & CXCL-11 & 1.16 & 1.73 \\
\hline ADIPOQ & 1.96 & 1.22 & GPI & 1.14 & 1.21 \\
\hline BMP-7 & 1.96 & 1.22 & ACTB & 1.13 & 0.95 \\
\hline CCL-11 & 1.96 & 1.22 & $\mathrm{~B} 2 \mathrm{M}$ & 1.13 & 1.22 \\
\hline CCL-18 & 1.96 & 1.22 & NODAL & 1.08 & 0.90 \\
\hline CCL-2 & 1.96 & 1.22 & IL-11 & 1.07 & 0.67 \\
\hline CCL-21 & 1.96 & 1.22 & $\mathrm{C} 5$ & 0.98 & 1.16 \\
\hline CCL-22 & 1.96 & 1.22 & CCL-1 & 0.97 & 1.11 \\
\hline CCL-24 & 1.96 & 1.22 & IL-21 & 0.94 & 0.89 \\
\hline
\end{tabular}


B

\begin{tabular}{|c|c|c|c|c|c|}
\hline Gene & $\begin{array}{l}\text { Fold induction } \\
\text { by } 12 \mathrm{e}\end{array}$ & $\begin{array}{l}\text { Fold induction by } \\
\text { IFN- } \alpha\end{array}$ & Gene & $\begin{array}{l}\text { Fold induction } \\
\text { by } 12 \mathrm{e}\end{array}$ & $\begin{array}{l}\text { Fold induction by } \\
\text { IFN- } \alpha\end{array}$ \\
\hline TLR-7 & 7.75 & 10.14 & AZI-2 & 1.15 & 1.88 \\
\hline IRAK-1 & 6.03 & 2.40 & CD-80 & 1.15 & 0.93 \\
\hline DDX-58 & 4.24 & 20.57 & TBK-1 & 1.14 & 1.39 \\
\hline CXCL-8 & 3.68 & 4.32 & TICAM-1 & 1.12 & 1.78 \\
\hline CASP-1 & 2.99 & 3.15 & ATG-5 & 1.08 & 1.54 \\
\hline SPP-1 & 2.84 & 3.22 & TRAF-6 & 1.07 & 1.40 \\
\hline CTSS & 2.82 & 4.09 & MX-1 & 1.06 & 484.86 \\
\hline TNF- $\alpha$ & 2.55 & 1.11 & MAP2K-1 & 1.03 & 0.6 \\
\hline JUN & 2.47 & 2.10 & ACTB & 1.02 & 0.98 \\
\hline PIN-1 & 2.40 & 0.76 & PSTPIP-1 & 0.98 & 1.54 \\
\hline CXCL-10 & 2.36 & 3.54 & STAT-1 & 0.94 & 7.36 \\
\hline MAP3K-1 & 2.35 & 1.70 & CXCL-9 & 0.93 & 1.78 \\
\hline IKBKB & 2.27 & 1.94 & IRF-3 & 0.93 & 0.74 \\
\hline IFIH-1 & 2.25 & 70.95 & ISG-15 & 0.91 & 64.38 \\
\hline FOS & 2.22 & 1.82 & SUGT-1 & 0.88 & 1.28 \\
\hline DAK & 2.06 & 1.63 & RPLP-0 & 0.75 & 0.67 \\
\hline MAVS & 1.77 & 1.72 & MAP2K-3 & 0.73 & 1.01 \\
\hline IL-18 & 1.75 & 2.68 & HSP90AA-1 & 0.69 & 1.04 \\
\hline NF-kBIA & 1.71 & 1.44 & HPRT-1 & 0.64 & 0.68 \\
\hline MAPK-3 & 1.66 & 1.18 & CXCL-11 & 0.56 & 7.46 \\
\hline MAPK-14 & 1.59 & 1.45 & APOBEC3G & 0.55 & 0.93 \\
\hline GAPDH & 1.56 & 1.17 & CARD-9 & 0.55 & 0.93 \\
\hline CASP-10 & 1.55 & 1.61 & CCL-3 & 0.55 & 0.93 \\
\hline IRF-5 & 1.54 & 0.93 & CCL-5 & 0.55 & 3.24 \\
\hline IL-12a & 1.52 & 1.81 & $\mathrm{CD}-40$ & 0.55 & 0.93 \\
\hline MYD-88 & 1.51 & 1.93 & CD-86 & 0.55 & 0.93 \\
\hline CASP-8 & 1.49 & 2.20 & $\mathrm{CD}-40$ & 0.55 & 0.93 \\
\hline TRAF-3 & 1.49 & 1.53 & CD-86 & 0.55 & 0.93 \\
\hline NF-kB1 & 1.47 & 1.5 & DHX-58 & 0.55 & 0.93 \\
\hline IL-15 & 1.45 & 3.19 & IFN- $\alpha 1$ & 0.55 & 0.93 \\
\hline CHUK & 1.43 & 1.28 & IFN- $\alpha 2$ & 0.55 & 0.93 \\
\hline FADD & 1.42 & 1.61 & IFN- $\beta 1$ & 0.55 & 0.93 \\
\hline MAP3K7 & 1.41 & 1.12 & IL- $12 \beta$ & 0.55 & 0.93 \\
\hline IFN-aR1 & 1.39 & 1.21 & IL- $1 \beta$ & 0.55 & 0.93 \\
\hline CTSL-1 & 1.38 & 1.63 & IL-6 & 0.55 & 1.07 \\
\hline DDX3X & 1.36 & 1.50 & IRF-7 & 0.55 & 0.93 \\
\hline TRIM-25 & 1.35 & 5.27 & NLRP-3 & 0.55 & 0.93 \\
\hline MAPK-8 & 1.30 & 1.33 & NOD-2 & 0.55 & 0.93 \\
\hline $\mathrm{B} 2 \mathrm{M}$ & 1.30 & 1.90 & OAS-2 & 0.55 & 224.36 \\
\hline PYCARD & 1.27 & 0.93 & PYDC-1 & 0.55 & 0.93 \\
\hline MAPK-1 & 1.26 & 1.34 & TLR-8 & 0.55 & 0.93 \\
\hline RIPK-1 & 1.17 & 1.11 & TLR-9 & 0.55 & 0.93 \\
\hline CTSB & 1.16 & 1.51 & TRADD & 0.53 & 1.4 \\
\hline TLR-3 & 1.16 & 5.65 & & & \\
\hline
\end{tabular}


Table 2. Chemical structures of trans-3-indole acrylate derivatives including $2 \mathrm{~b}, 8,10,11$, and $12 \mathrm{a}$<smiles>[R]C(=O)/C([R])=C/c1c[nH]c2ccccc12</smiles>

\begin{tabular}{lll}
\hline \multirow{2}{*}{ Code No. } & $\mathrm{R}_{1}$ & Structure \\
\cline { 2 - 4 } & $\mathrm{Me}$ & $\mathrm{Me}$ \\
10 & $\mathrm{Me}$ & $\mathrm{Me}$
\end{tabular}

$\mathrm{Me}=\operatorname{Methyl}\left(\mathrm{CH}_{3}\right)$.

Table 3. Chemical structures of indole 2-methylacrylamide derivatives including $12 \mathrm{c}, 12 \mathrm{~d}, 12 \mathrm{e}$, and $12 \mathrm{~g}$

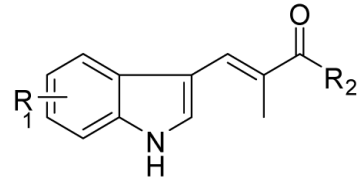

\begin{tabular}{lcc}
\hline Code No & \multicolumn{2}{c}{ Structure } \\
\cline { 2 - 3 } $12 \mathrm{c}$ & $\mathrm{R}_{1}$ & $\mathrm{Me}$ \\
$12 \mathrm{~d}$ & $5-\mathrm{OMe}$ \\
$12 \mathrm{e}$ & $5-\mathrm{CN}$ \\
$12 \mathrm{~g}$ & \\
\hline
\end{tabular}

$\mathrm{Me}=\operatorname{Methyl}\left(\mathrm{CH}_{3}\right)$
Western blot analysis. $1.5 \times 10^{5}$ Huh7.5-J6/JFH1 or Bart79I cells were plated onto a 6-well plate (Costar 3610) and supplemented with DMSO or compound 12e with indicated concentrations. At 5 days after incubation, whole-cell extracts were prepared in RIPA buffer $(150 \mathrm{mmol} / \mathrm{l} \mathrm{NaCl}, 1 \%$ Triton X-100, $1 \%$ deoxycholic acid sodium salt, $0.1 \%$ SDS, $50 \mathrm{mmol} / \mathrm{l}$ Tris- $\mathrm{HCl}, \mathrm{pH}$ 7.5, $2 \mathrm{mmol} / \mathrm{l}$ EDTA; genDEPOT) containing a cocktail of protease inhibitors (Complete, Roche Diagnostic at final concentration of 1 tablet per $50 \mathrm{ml}$ RIPA buffer) and quantitated by the Bradford assay (Bio-Rad). Equal amounts of protein were electrophoresed on an SDS-PAGE, subsequently transferred to a polyvinylidene difluoride membrane (Immobilon-P; Millipore, Bedford), and probed with a mouse anti-NS3 monoclonal antibody (1:1000, MAb 1847 for NS3, Virostat). Proteins were visualized via enhanced chemiluminescence (Amersham Pharmacia).

PCR array analyses. Total RNA was isolated from Huh7.5-J6/ JFH1 cells treated with either DMSO or 12e for 3 days. The quality of isolated RNA was confirmed by spectrophotometric analysis of 260/280nm UV absorbance ratio. PCR array analyses were performed on isolated RNA using cytokine and anti-viral PCR array kits (PHAS-122ZE and PHAS-150ZE, Qiagen) according to the manufacturer's instructions. All individual experimental data were analyzed using the recommended software.

Effect of $12 e$-treated media on HCV replication. $3 \times 10^{6} \mathrm{Huh}-7.5$ cells were seeded in a $10 \mathrm{~cm}$ plate and supplemented with either DMSO or $10 \mu \mathrm{mol} / \mathrm{l}$ of compound 12e. After 2 days of incubation, cells were incubated with $12 \mathrm{e}$-free media for additional 2 days to collect media containing secreted cytokines. After $3 \times 10^{3}$ Huh7.5-Rluc-J6/JFH1 cells were plated onto a white 96-well plate, these media were then transferred to Huh7.5-Rluc-J6/JFH1 cells to examine their effect on $\mathrm{HCV}$ replication by performing renilla luciferase and cytotoxicity assays after 3 days of incubation.

FACS analysis. FACS analysis was conducted as described previously (Min et al., 2012). Briefly, $3 \times 10^{5}$ Huh7.5, Huh7.5-J6/JFH1, or Huh7.5-Bart79I cells were plated onto a 6-well plate (Costar 3516) and supplemented with either DMSO or $10 \mu \mathrm{mol} / \mathrm{l}$ of $12 \mathrm{e}$. After 3 days of incubation, cells were fixed at room temperature for $20 \mathrm{~min}$ in $4 \%$ paraformaldehyde, permeabilized in $0.1 \%$ Triton-X in PBS for $5 \mathrm{~min}$, rinsed three times in PBS, and blocked with PBS with 2\% FBS. A mouse anti-CXCL-8 antibody (M801, Thermo Scientific) was diluted in blocking buffer, and the mixture was incubated for overnight at $4^{\circ} \mathrm{C}$. After three washes in PBS, cells were incubated with an Alexa 488-conjugated anti-mouse IgG secondary antibody (Invitrogen, Carlsbad, CA) for $1 \mathrm{hr}$. Following three washes with PBS, cells were resuspended in PBS. FACS analysis was performed by the FACSAria 3 system (BD, USA).

ELISA of CXCL-8 protein. $1.5 \times 10^{5}$ Huh7.5, Huh7.5-J6/JFH1 or Bart79I cells were plated onto a 6-well plate (Costar 3610) and supplemented with DMSO or compound 12e with indicated concentrations for 3 days. The concentration of CXCL-8 protein in media was measured using human IL-8 ELISA kit (Thermo Scientific). The analysis was performed according to the manufacturer's protocol. 
(a)

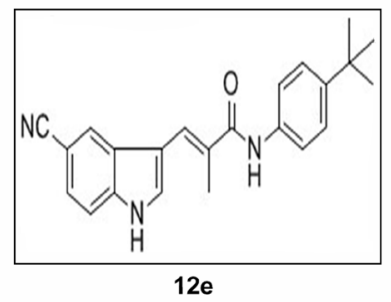

(c)

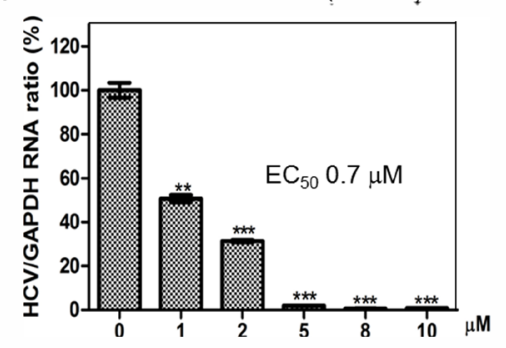

(d)

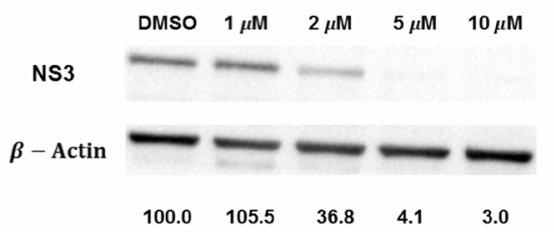

(b)

Huh7.5-Rluc-J6/JFH1 (GT 2a)

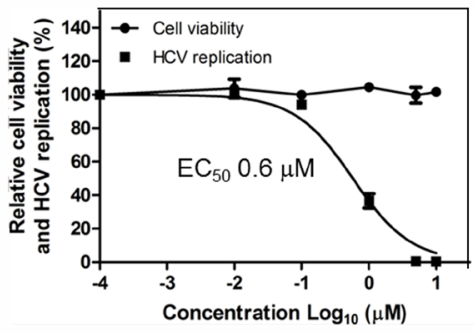

Huh7.5-Bart79I (GT 1b)

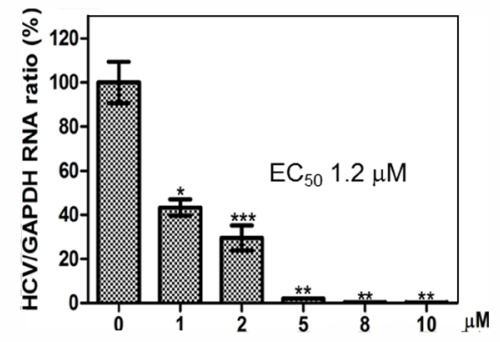

Huh7.5-Bart79| (GT1b)

DMSO $\quad 1 \mu \mathrm{M} \quad 2 \mu \mathrm{M} \quad 5 \mu \mathrm{M} \quad 10 \mu \mathrm{M}$

NS3

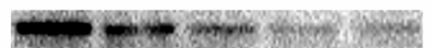

$\beta$ - Actin

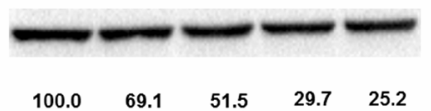

Fig. 1

Inhibition of HCV replication by $12 \mathrm{e}$

(a) The chemical structure of compound 12e (b) Dose-response curve was determined by assaying relative cell viability and luciferase activity in Rluc-J6/ JFH1 RNA-transfected Huh7.5 cells treated with increasing concentrations of the compound 12e for $72 \mathrm{hr}$. (c) Dose-response graphs were determined by assaying relative HCV as well as GAPDH RNA levels via qRT-PCR analysis of either J6/JFH1 or Bart79I RNA-transfected Huh7.5 cells treated with increasing concentrations of the compound $12 \mathrm{e}$ for $72 \mathrm{hr}$. The statistical significance of differences relative to controls (DMSO) is indicated as ${ }^{*} \mathrm{p}<0.1$, ${ }^{* *} \mathrm{p}<0.01$ or ${ }^{* * *} \mathrm{p}<0.001$ by Student's $\mathrm{t}$ test. (d) Dose-response was determined by assaying relative levels of HCV NS3 as well as host $\beta$-actin proteins via Western blot analyses of either J6/JFH1 or Bart79I RNA-transfected Huh7.5 cells treated with increasing concentrations of the compound $12 \mathrm{e}$ for $120 \mathrm{hr}$. Error bars represent SD values. GT = genotype.

Effect of a recombinant CXCL-8 protein on HCV replication. $1.8 \times 10^{4}$ Huh7.5-Rluc-J6/JFH cells were plated onto a white 96-well plate (Costar 3610) and supplemented with DMSO or a recombinant CXCL-8 protein at a concentration starting in the range from $2 \mathrm{pg} / \mathrm{ml}$ to $20 \mathrm{ng} / \mathrm{ml}$ (GTX48422-PRO, GeneTex). After 3 days of incubation, cells were incubated for $3 \mathrm{hr}$ at $37^{\circ} \mathrm{C}$ in the presence of EZ-CYTOX (10\% tetrazolium salt; Dogen) reagent to assess the cytotoxicity. Renilla luciferase activities were measured using a luciferase reagent ( $1 \mathrm{mmol} / \mathrm{l}$ coelenerazine in Methanol-HCL, Goldbio).

CXCL-8 promoter reporter assay. An IL-8 promoter-luciferase reporter vector (pGL3-pIL-8) was transfected into Huh7.5-Rluc-J6/ JFH1 cells. The transfected cells were then treated with $10 \mu \mathrm{mol} / \mathrm{l}$ of indole compound for $48 \mathrm{hr}$. A dual luciferase assay was conducted using Glomax dual luciferase assay kit (Promega) to simultaneously measure the firefly luciferase for CXCL-8 promoter activity and the renilla luciferase for $\mathrm{HCV}$ replication.

\section{Results}

\section{$12 e$ inhibits $H C V$ replication}

Before we started the study of the mechanism of action for compound 12e (its chemical structure shown in Fig. 1a), we decided to reconfirm its anti-HCV replication activ- 
ity. For this purpose, Huh7.5 hepatocarcinoma cells were transfected with renilla luciferase-linked J6/JFH1 RNAs (Huh7.5-Rluc-J6/JFH1 (genotype (GT) 2a)) (Tscherne et al., 2006) and the luciferase activity was measured to assess the HCV RNA replication levels. As shown in Fig. 1b, treatment with $12 \mathrm{e}$ at the concentration of $0.6 \mu \mathrm{mol} / \mathrm{l}\left(\mathrm{EC}_{50}\right)$ was able to suppress HCV replication by half without any significant cytotoxicity until $10 \mu \mathrm{mol} / \mathrm{l}$. A reporter-free infectious clone system (Huh7.5-J6/JFH1 (GT 2a)) as well as a subgenomic replicon system (Huh7.5-Bart79I (GT 1b)) reached a similar range of $\mathrm{EC}_{50}$ values $(0.7 \mu \mathrm{mol} / \mathrm{l}$ and 1.2 $\mu \mathrm{mol} / \mathrm{l}$, respectively) by qRT-PCR analyses (Fig. 1c). The dose-dependent down-regulation of expression of a viral protein, NS3, upon the treatment with an increasing dose of $12 \mathrm{e}$ was further confirmed by two sets of Western blot analyses using Huh7.5-J6/JFH1 as well as Huh7.5-Bart79I cells (Fig. 1d). These data demonstrated a potent inhibitory activity of $12 \mathrm{e}$ against HCV replication.

\section{$12 e$ activates pro-inflammatory and antiviral cytokine genes}

Induction of host antiviral cytokine genes by viral infection plays a major role in combating viral replication in host cells. Especially, several well-characterized anti-HCV therapeutics including IFN- $\alpha$ and ribavirin were shown to exhibit their antiviral activities through induction of specific host antiviral cytokine genes at the transcriptional level (Tokumoto et al., 2012). After reconfirming suppression of $\mathrm{HCV}$ replication by $12 \mathrm{e}$, we hypothesized that $12 \mathrm{e}$ might be able to alter transcriptional profiles of key host cytokines as well as antiviral genes in order to facilitate its antiviral activity. To verify this hypothesis, we performed two sets of PCR array analyses, which enabled us to examine effects of $12 \mathrm{e}$ on transcriptional levels of 84 cytokines (Table 1A) and 87 antiviral (Table 1B) genes from Huh7.5-J6/JFH1 cells. As shown in Table 1B, well-known IFN- $\alpha$-responsive genes including MX1 (484.85-fold), OAS2 (224.36-fold), IFIH1 (70.95-fold), ISG15 (64.38-fold), DDX58 (20.57-fold), and TLR7 (10.14 fold) were highly induced by treatment with $10 \mathrm{pg} / \mathrm{ml}$ of IFN- $\alpha$, validating the specificity of these PCR array analyses. Interestingly, $12 \mathrm{e}$ was able to activate transcription of a subset of pro-inflammatory genes including CXCL-8 (6.67-fold), IL-1 $\alpha$ (5.98-fold), TNF- $\alpha$ (5.69-fold), and IL-3 (4.64-fold), and antiviral genes including TLR-7 (7.75-fold), IRAK-1 (6.03-fold), DDX-58 (4.24-fold), and CXCL-8 (3.68-fold). Especially, CXCL-8 gene showed the first and fifth highest fold-induction values among cytokine and antiviral genes induced by treatment of $12 \mathrm{e}$, respectively. In order to verify the transcriptional activation of these seven individual genes by $12 \mathrm{e}$, we also conducted a series of individual qRT-PCR analyses. As shown in Fig. 2, the dosedependent increase in the mRNA levels of CXCL-8, TNF- $\alpha$, IL-3, TLR-7, and IRAK-1 genes after the treatment with 12e was further confirmed except for IL-1 $\alpha$. These data suggest that $12 \mathrm{e}$ is able to activate transcription of a subset of key pro-inflammatory and antiviral cytokine genes.

$12 e$ stimulates extracellular secretion of soluble factors leading to the suppression of $\mathrm{HCV}$ replication

After confirming transcriptional up-regulation of a unique subset of cytokine genes, we hypothesized that $12 \mathrm{e}$ might be able to stimulate extracellular secretion of specific cytokine proteins, which might be responsible for indirect inhibition of HCV replication by $12 \mathrm{e}$ via a paracrine manner. To test this hypothesis, Huh7.5 cells were treated with either DMSO or $12 \mathrm{e}$ for $48 \mathrm{hr}$, and then incubated with drug-free fresh media for another $48 \mathrm{hr}$. These conditioned media were then transferred to Huh7.5-Rluc-J6/JFH1 cells to examine their effect on HCV replication. Unlike DMSO-pretreated media (Fig. 3a), 12e-treated media showed a strong inhibitory activity against $\mathrm{HCV}$ replication in a dose-dependent manner without any major effect on cell viability (Fig. 3b). The dose-dependent 12e-specific antiviral activity was more evident when relative cell viability and HCV replication values were plotted as a ratio (Fig. $3 \mathrm{c}$ ). These data suggest that $12 \mathrm{e}$ is able to stimulate secretion of soluble factors with anti-HCV replication activities.

Transcriptional activation of CXCL-8 gene by indole derivatives correlates with their antiviral potentials

According to our previous PCR array analyses, CXCL-8 was the only gene whose transcriptional activation was validated in both pro-inflammatory and antiviral PCR array analyses. Therefore, we decided to focus on a potential role of CXCL-8 gene in the suppression of HCV replication by $12 \mathrm{e}$. In order to study a direct relationship between transcriptional activation of CXCL- 8 and down-regulation of HCV replication by $12 \mathrm{e}$ in a more detailed manner, we treated Huh7.5-J6/JFH1 and Huh7.5-Bart79I cells with an increasing dose of 12e and examined levels of CXCL-8 mRNA and HCV RNA simultaneously. As expected, both Huh7.5-J6/JFH1 and Huh7.5-Bart79I cells exhibited around 8- and 3-fold increase, respectively, in the amount of CXCL- 8 mRNAs upon the treatment with $10 \mu \mathrm{mol} / \mathrm{l}$ of $12 \mathrm{e}$ (Fig. $4 \mathrm{a}$ and $4 \mathrm{~b}$ ). In addition, we were also able to observe a sharp decrease in HCV RNA levels in both Huh7.5-J6/JFH1 and Huh7.5-Bart79I cells treated with 12e. Even Huh7.5 cells without any HCV genome showed a robust increase in CXCL-8 mRNA level upon treatment of 12e in a dose-dependent manner (Fig. 4c). Of note, BMS-790052, an NS5A inhibitor did not affect a transcriptional level of CXCL-8 gene despite its superior inhibitory potency against HCV replication (Fig. 4a,b,c). These data imply that transcriptional activation of CXCL- 8 gene by $12 \mathrm{e}$ is not due to a mere indirect result of the loss of HCV replication. 
In order to further validate this negative relationship between transcriptional activation of CXCL- 8 gene and HCV replication, we examined the effects of other previously identified indole derivatives on levels of CXCL- 8 mRNA. For this purpose, we used a qRT-PCR analysis as well as a CXCL-8 promoter-linked luciferase reporter assay. As shown in Fig. 5a, two indole compounds such as $12 \mathrm{a}$ (chemical structure shown in Table 2) and 12e, which exhibited strongest antiviral potencies, also showed highest level of a transcriptional activation of CXCL- 8 gene. On the other hand, three other indole compounds $-2 \mathrm{~b}, 8$, and 10 (chemical structures shown in Table 2 ), which exhibited weaker antiviral potencies - also showed lower levels of a transcriptional activation of CXCL- 8 gene. This trend was also true for other compounds including $12 \mathrm{c}, 12 \mathrm{~d}$, $12 \mathrm{e}$, and $12 \mathrm{~g}$ (structures shown in Table 3 ). Their high CXCL-8 promoter-stimulating activities always resulted in potent antiviral capabilities in Huh7.5-Rluc-J6/JFH1 cells (Fig. 5b). These data strongly suggest that the induction CXCL- 8 gene is closely linked with the inhibition of HCV replication by indole derivatives.

Transcriptional activation of CXCR-8 gene by $12 \mathrm{e}$ leads to the induction of CXCR-8 protein

Based on previous results, we hypothesized that the transcriptional activation of CXCL- 8 gene by $12 \mathrm{e}$ should lead
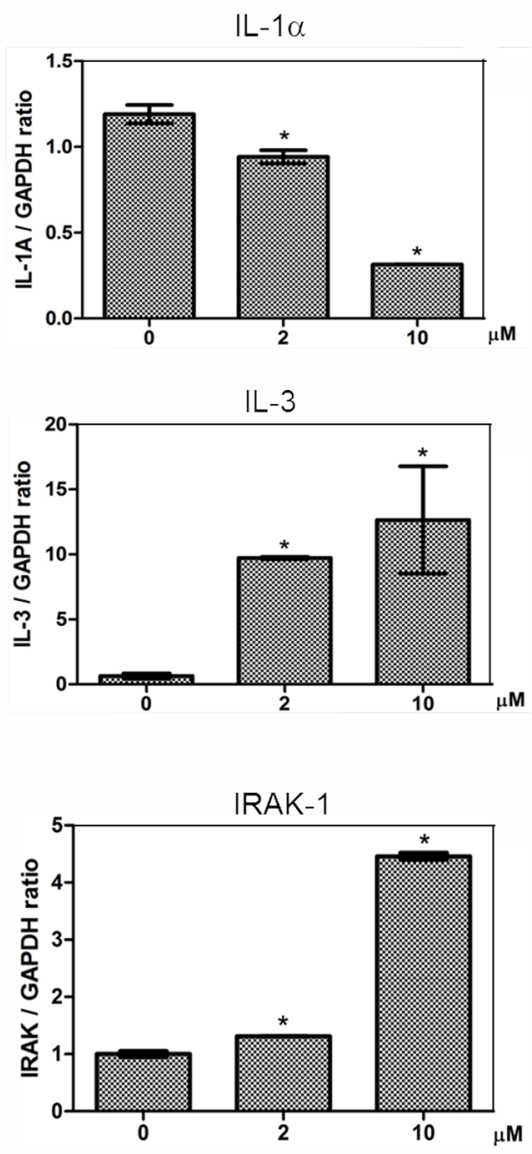

Fig. 2

Effect of $12 \mathrm{e}$ on the transcriptional levels of pro-inflammatory and antiviral genes

PCR microarrays. Dose-response graphs were determined by assaying relative levels of CXCL-8, IL-1 $\alpha$, TNF- $\alpha$, IL-3, TLR-7, IRAK-1 and DDX-58 genes via qRT-PCR analysis of J6/JFH1 RNAtransfected Huh7.5 cells treated with increasing concentrations of the compound $12 \mathrm{e}$ for $72 \mathrm{hr}$. Error bars represent SD values. For statistical significance and error bars see above. 
to an increased extracellular secretion of CXCL-8 protein. In order to test this hypothesis, we decided to stain Huh7.5, Huh7.5-J6/JFH1, and Huh7.5-Bart79I cells with an antiCXCL-8 antibody after treatment with $12 \mathrm{e}$ for 3 days. An Alexa 488-conjugated polyclonal anti-mouse antibody was used as a secondary antibody for FACS analysis in order to quantitate the percentage of CXCR-8-positive cells. As shown in Fig. 6a, upon treatment with 12e, the number of CXCR-8-positive cells increased by 67,121 , and $20 \%$ in Huh7.5, Huh7.5-J6/FHJ1, and Huh7.5-Bart79I cells, respectively, when compared with DMSO-treated cells. A significant increase in the extracellular level of CXCR-8 protein upon treatment of 12e was further verified by ELISA analysis of extracellular levels of secreted CXCL-8 protein in the media from Huh7.5, Huh7.5-J6/FHJ1, and Huh7.5-Bart79I cells (Fig. 6b). Of note, BMS-790052 again failed to induce any CXCL-8 protein, suggesting suppression of $\mathrm{HCV}$ replication itself is not sufficient for induction of extracellular level of CXCL-8 protein. These data suggest that the transcriptional activation of CXCR- 8 gene by $12 \mathrm{e}$ leads to the induction and secretion of CXCR- 8 protein.

\section{Recombinant CXCL-8 protein partially reduces $\mathrm{HCV}$} replication

After confirming an indirect antiviral activity of extracellular proteins whose secretion was stimulated by $12 \mathrm{e}$, we tested whether CXCL-8 protein itself possesses a direct antiviral ac- tivity. For this purpose, we purchased a commercially available recombinant CXCL-8 protein. Specificity of this recombinant CXCL-8 protein was first confirmed by successful detection of 50 pg of CXCL-8 protein by Western blot analysis using an anti-CXCL-8 antibody (Fig. 7a), which was employed previously in our FACS analysis (Fig. 6a). Then, Huh7.5-Rluc-J6/ JFH1 cells were treated with an increasing concentration of this recombinant CXCL-8 protein to see if it has any direct effect on HCV replication. As shown in Fig. 7b, we observed around $30 \%$ reduction in the level of HCV replication upon the treatment with the recombinant CXCL- 8 protein at 200 $\mathrm{pg} / \mathrm{ml}$. This moderate inhibitory activity of CXCL- 8 against $\mathrm{HCV}$ replication was maintained up to $20 \mathrm{ng} / \mathrm{ml}$. These data suggest that the treatment with recombinant CXCL-8 proteins is able to induce a partial reduction in HCV replication.

\section{Discussion}

In this paper, we described that one of the most potent anti-HCV replication inhibitor with an indole moiety, 12e, was able to induce transcriptional activation of a number of pro-inflammatory as well as antiviral cytokine genes including CXCL-8, IL-1 $\alpha$, TNF- $\alpha$, IL-3, IRAK-1, DDX58, and TLR-7. In addition, we also found that secretion of soluble factors stimulated by $12 \mathrm{e}$ plays a significant role in suppression of $\mathrm{HCV}$ replication in $\mathrm{HCV}$-positive neigh- (a)

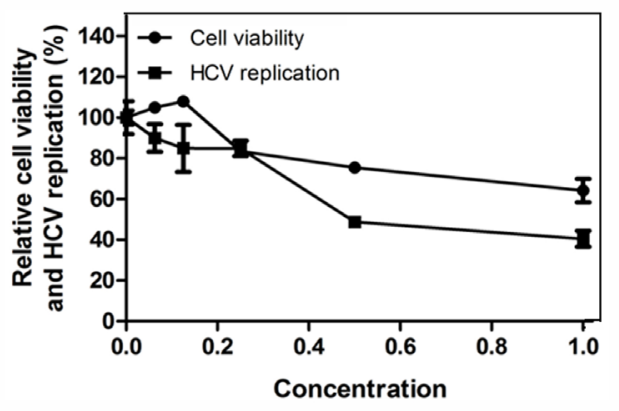

(c)

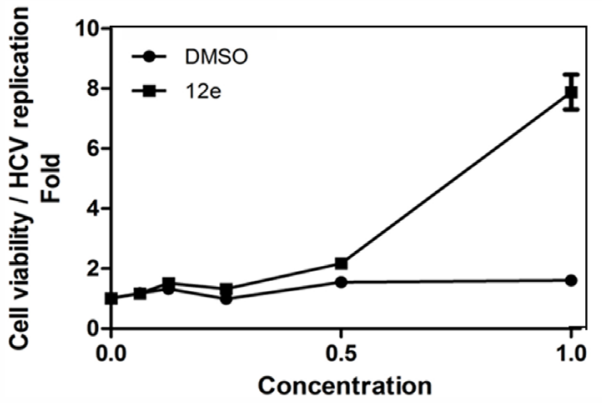

(b)

\section{$12 \mathrm{e}$-treated media}

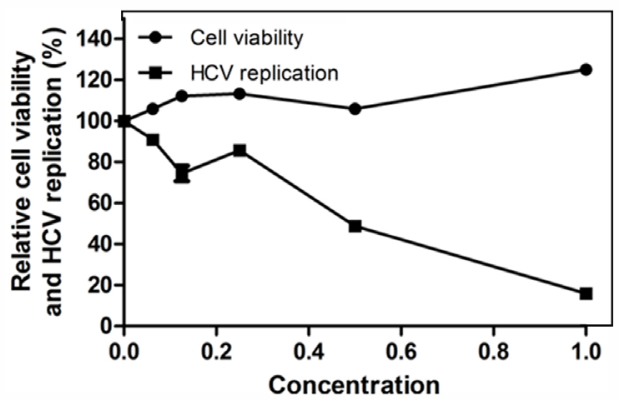

Fig. 3

Effect of 12e-treated medium on HCV replication Dose-response curve was determined by assaying relative cell viability (a) as well as luciferase activity (b) in Rluc-J6/JFH1 RNA-transfected Huh7.5 cells treated $\mathrm{w} /$ wo increasing concentrations of $12 \mathrm{e}$ in DMSO for $72 \mathrm{hr}$. Concentration 1.0 means undiluted medium. (c) Relative cell viability and $\mathrm{HCV}$ replication level plotted together by calculating their fold ratio. For error bars see above. 
boring cells. Existence of a strong positive correlation between transcriptional activation of CXCL-8 and antiviral potency by other members of this class of compounds was further validated by a qRT-PCR analysis and a CXCL- 8 promoter-linked luciferase reporter assay.Finally, direct treatment with a recombinant CXCL-8 protein also resulted in a moderate reduction in $\mathrm{HCV}$ replication. All these data strongly suggest that indole derivatives tested inhibit HCV replication through induction of a number of pro-inflammatory genes.

(a) Huh7.5-J6/JFH1 (GT 2a)

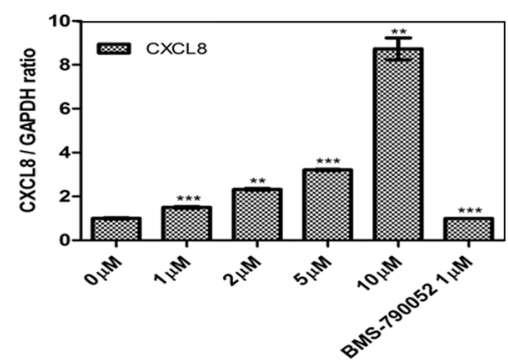

(b)

Huh7.5-Bart79| (GT 1b)

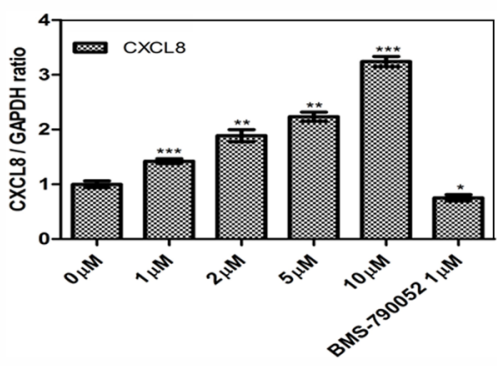

Ribavirin is a nucleotide analog with a broad range of antiviral capability against a number of RNA and DNA viruses (Sidwell et al., 1972). As explained previously, ribavirin has played a critical role in suppression of $\mathrm{HCV}$ infection as an essential component of the first line of HCV therapeutics together with pegylated IFN- $\alpha$, since ribavirin is able to eliminate HCV only when combined with IFN. However, its detailed mode of antiviral action has been elusive so far. A recent study demonstrated that ribavirin is able to regulate HCV replication through enhancing IFN-stimulated genes

(c)

Huh 7.5 without $\mathrm{HCV}$

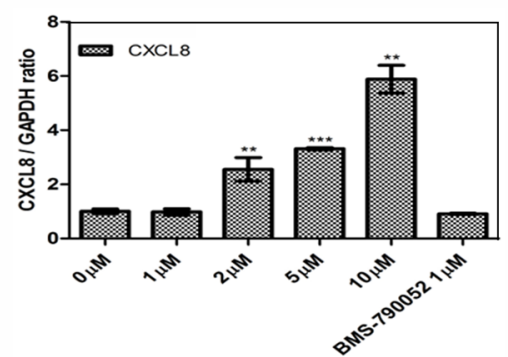

Fig. 4

Transcriptional induction of CXCL- 8 by $12 \mathrm{e}$

Dose-response graphs were determined by assaying relative CXCL-8, HCV as well as GAPDH RNA levels via qRT-PCR analysis of either J6/JFH1 (a) or Bart79I (b) RNA-transfected Huh7.5 cells treated with increasing concentrations of the compound 12e for $72 \mathrm{hr}$. NS5A inhibitor BMS-790052 (1 $\mu \mathrm{mol} / \mathrm{l}$ ) was used as a positive control for suppression of HCV replication. (c) A dose-response graph was determined by assaying relative CXCL-8 as well as GAPDH RNA levels via qRT-PCR analysis of Huh7.5 cells treated with increasing concentrations of the compound $12 \mathrm{e}$ for $72 \mathrm{hr}$. For error bars and statistical significance see above. 
(ISGs) and CXCL-8 (Tokumoto et al., 2012). In this paper, the authors measured mRNA levels of ISGs in T lymphocytes from patients with HCV infection, who were receiving IFN- $\alpha$ therapy with or without ribavirin. They found that average levels of CXCL-8 mRNA were much higher in IFN- $\alpha$ - and ribavirin-treated patients than in those treated with IFN- $\alpha$ alone. In addition, the up-regulation of CXCL-8 expression by ribavirin was confirmed in three $\mathrm{HCV}$ replicon cells regardless of IFN-a treatment (Tokumoto et al., 2012). In this regard, compound $12 \mathrm{e}$ has a high degree of similarity to ribavirin in the antiviral mode of action, since both of them require enhanced transcription of CXCL- 8 gene in order to exert their antiviral activity. It would be interesting to see what kind of effect a co-treatment with $12 \mathrm{e}$ and ribavirin would have on $\mathrm{HCV}$ replication. If the transcriptional activation of CXCL- 8 gene is the major mechanism of action for both molecules, we expect that there would be no additive or synergistic down-regulation of HCV replication after the co-treatment with $12 \mathrm{e}$ and ribavirin.

Regulation of CXCL-8 expression is a complicated process working at both transcriptional and post-transcriptional levels (Koo et al., 2006). CXCL-8 induction requires either transcriptional activation of CXCL-8 promoter or stabilization of CXCL-8 mRNA (Holtmann et al., 1999). Therefore, an increase in CXCL-8 mRNA levels after the treatment with $12 \mathrm{e}$ might be due to the direct up-regulation of either transcription factors involved in CXCL-8 promoter activation or other host factors involved in regulation of CXCL-8 (a)

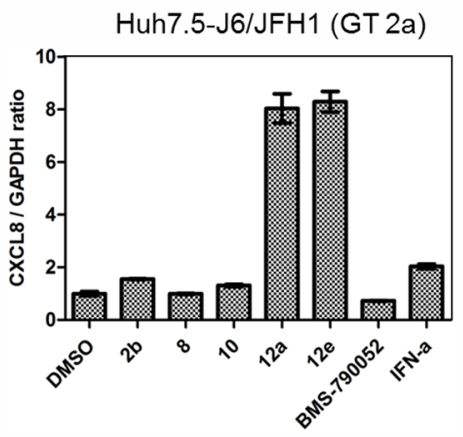

(b)

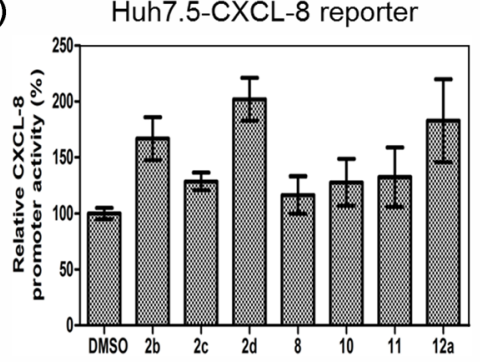

Huh7.5-CXCL-8 reporter

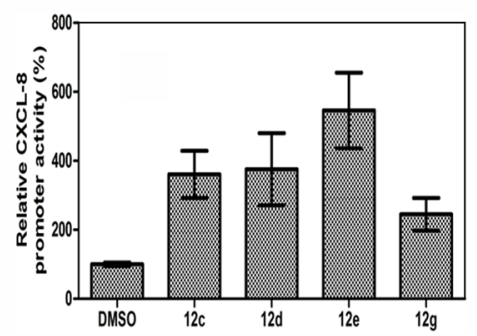

Huh7.5-J6/JFH1 (GT 2a)

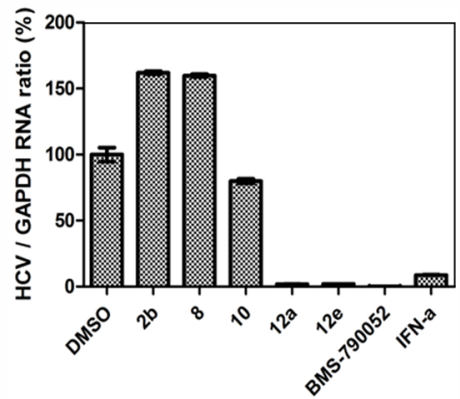

Huh7.5-Rluc-J6/JFH1 (GT 2a)

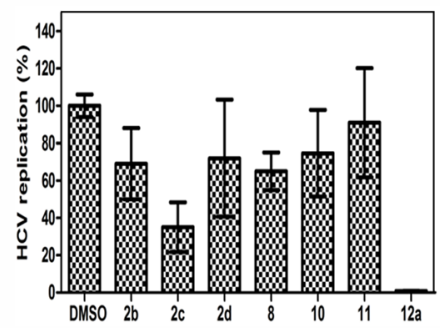

Huh7.5-Rluc-J6/JFH1 (GT 2a)

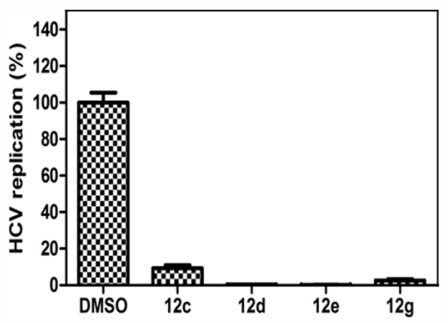

Fig. 5

Inverse correlation between transcriptional induction and $\mathrm{HCV}$ replication by $12 \mathrm{e}$

(a) Dose-response graphs were determined by assaying relative CXCL-8, HCV as well as GAPDH RNA levels via qRT-PCR analysis of J6/JFH1 RNAtransfected Huh7.5 cells treated with $10 \mu \mathrm{mol} / \mathrm{l}$ of compounds $2 \mathrm{~b}, 8,10,12 \mathrm{a}$ and $12 \mathrm{e}$ for $72 \mathrm{hr}$. (b) Dose-response graphs were determined by assaying relative CXCL-8 promoter activity and HCV replication levels via dual luciferase analysis of both CXCL-8 promoter-linked firefly luciferase reporter DNA and Rluc-J6/JFH1 RNA-transfected Huh7.5 cells treated with $10 \mu \mathrm{mol} / \mathrm{l}$ of compounds $2 \mathrm{~b}, 2 \mathrm{c}, 2 \mathrm{~d}, 8,10,11,12 \mathrm{a}, 12 \mathrm{c}, 12 \mathrm{~d}, 12 \mathrm{e}$, and $12 \mathrm{~g}$ for $72 \mathrm{hr}$. For BMS-790052 and error bars see above. 
mRNA stability. A number of transcription factors including NF-kB, IRFs, AP-1, and C/EBP have been showed to be necessary for transcription activation of CXCL- 8 gene (Casola et al., 2000). Therefore, in order to answer which transcription factor is targeted by $12 \mathrm{e}$, a series of CXCL- 8 promoter-linked luciferase reporters lacking binding sites for each transcription factor need to be constructed in the future. On the other hand, CXCL- 8 expression also involves AU-rich elements in 3'-untranslated region that regulates mRNA stability (Green et al., 2006). In this regard, it would be also interesting to see whether $12 \mathrm{e}$ exerts any positive effect on regulation of CXCL- 8 mRNA stability through altered binding of host factors on these AU-rich elements in 3'-untranslated region of CXCL- 8 mRNA.

CXCL-8 serves as one of the major chemokines that send a chemical signal to attract neutrophils to the site of inflammation (Van Damme et al., 1989). One possible benefit of $12 \mathrm{e}$-induced transcriptional activation of CXCL- 8 gene would be to stimulate neutrophils, which are attracted by CXCL-8, to digest HCV antigens, which in turn results in increased IFN- $\alpha$ and ISG production in vivo. Interestingly, we were not able to see an increase in secretion of CXCL-8 protein in the macrophage cell line (RAW 264.7) treated with $12 \mathrm{e}$ (data not shown). This suggests that there is an

(a)
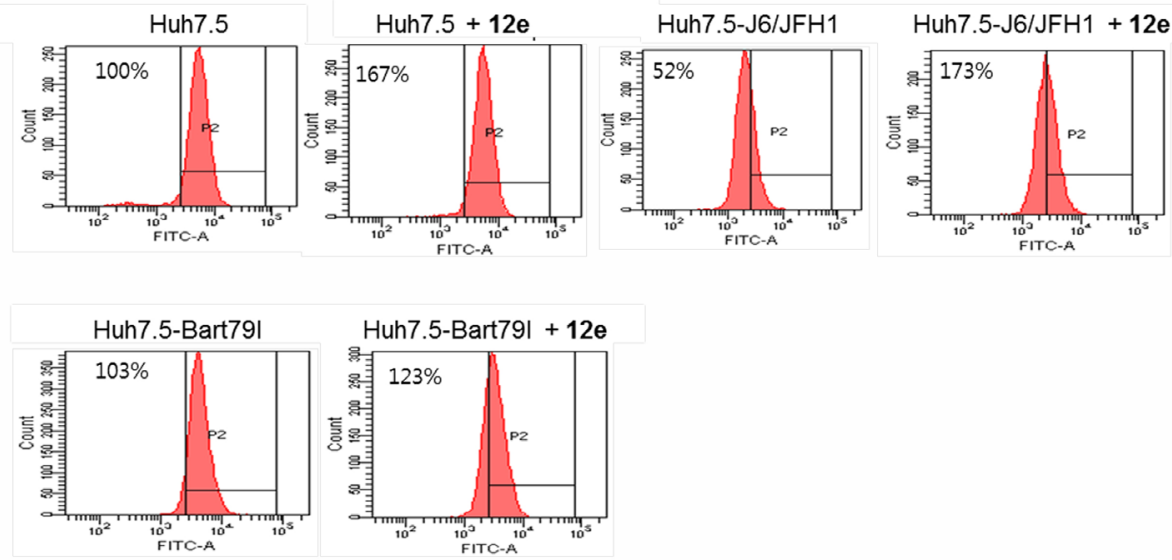

(b)

Huh7.5

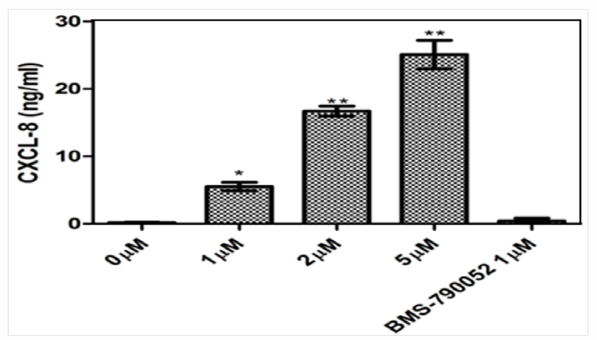

Huh7.5-Bart79I (GT 1b)

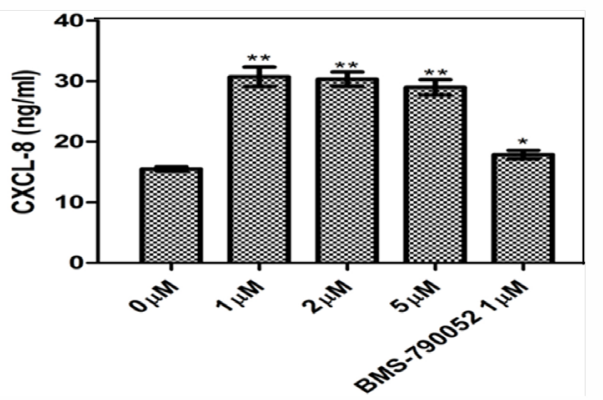

Huh7.5-J6/JFH1 (GT 2a)

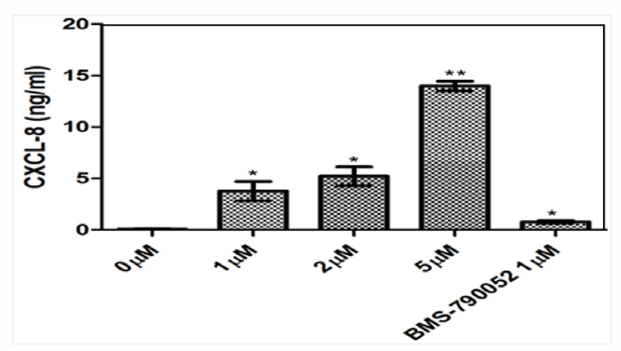

Fig. 6

Effect of the compound 12e on CXCX-8 protein expression

(a) Huh7.5, Huh7.5-J6/JFH1, or Huh7.5-Bart79I cells were treated with either DMSO or $10 \mu \mathrm{mol} / \mathrm{l}$ of $12 \mathrm{e}$ for 3 days. Cells were fixed and stained with a mouse anti-CXCL- 8 antibody and an Alexa 488-conjugated anti-mouse IgG secondary antibody. FACS analysis was performed to quantitate the percentage of CXCL-8-positive cells. (b) Huh7.5, Huh7.5-J6/JFH1 or Huh7.5-Bart79I cells were treated with either DMSO or $10 \mu \mathrm{mol} / 1$ of $12 \mathrm{e}$ for 3 days. Conditioned cell culture media were assayed for CXCL-8 protein by ELISA. 
(a)

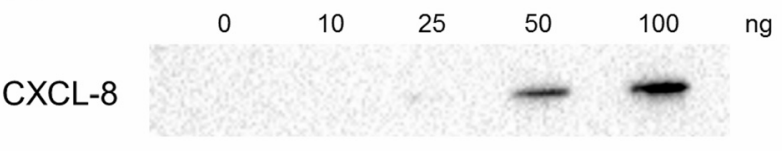

(b)

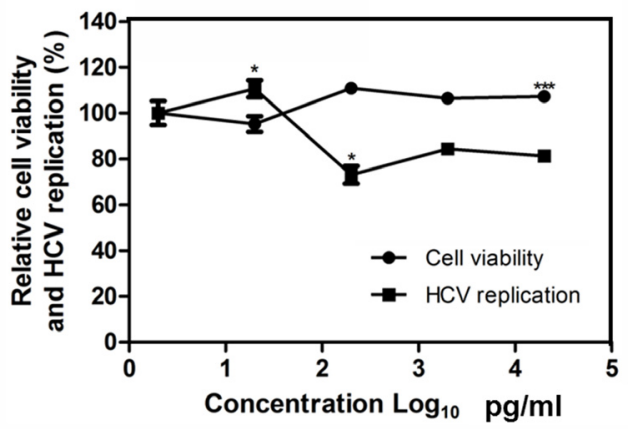

Fig. 7

Effect of the recombinant CXCX-8 protein on $\mathrm{HCV}$ replication (a) A fixed amount of recombinant CXCX-8 protein (0, 10, 25, 50, and 100 pg) was tested for its reactivity with anti-CXCL- 8 antibody by Western blot analysis. (b) Huh7.5-Rluc-J6/JFH1 cells were treated with an increasing concentration of the recombinant CXCL- 8 protein for 3 days. Relative cell viability and HCV replication were determined by MTT and renilla luciferase assays.

intrinsic difference in the way of transcriptional activation of CXCL-8 gene in the liver and in immune cells.

It has been well known that there is a positive relationship between HCV replication and CXCL-8 production (Koo et al., 2006). In this regard, the up-regulation of CXCL-8 induced by $12 \mathrm{e}$ would not help elimination of HCV infection. In the worst scenario, this might lead to the weakening of the antiviral efficacy of other co-administered anti-HCV drugs. Moreover, CXCL-8 was shown to play a major role in induction of inflammatory response such as viral hepatitis. Our observation of a negative relationship between HCV replication and transcriptional activation of CXCL-8 gene seems to be a sharp contrast to the previous observations. One plausible explanation for this discrepancy might be based on the following hypothesis. HCV may need to intentionally increase the amount of CXCL-8 up to a certain level to support its optimal RNA replication. Excessive up-regulation of CXCL-8 induced by the treatment with 12e might surpass this optimal concentration of CXCL-8 required for HCV replication and this might lead to a deleterious outcome to the $\mathrm{HCV}$ replication. We are now in the process of performing relevant experiments to test this hypothesis. In addition, confirming the antiviral efficacy of $12 \mathrm{e}$ using a humanized liver mouse model would help us to understand a detailed antiviral mechanism of action for 12e in the context of more in-vivo-like setting.
We were only able to see a partial reduction of HCV replication after the treatment with the recombinant CXCL-8 protein. We were not able to increase the concentration of the recombinant CXCL-8 protein to more than $20 \mathrm{ng} / \mathrm{ml}$ due to the restrictions resulting from the original concentration of the recombinant CXCL-8 protein. Treatment with $5 \mu \mathrm{mol} / \mathrm{l}$ of $12 \mathrm{e}$ increased the extracellular concentration of CXCL- 8 to up to $25 \mathrm{ng} / \mathrm{ml}$. These data indicate that CXCL-8 protein alone may not be enough to suppress the HCV replication by itself. CXCL-8 may rather need to work together with other pro-inflammatory cytokines such as IL- $1 \alpha$, TNF- $\alpha$, IL-3, IRAK-1, and DDX58 in order to achieve the full repression of $\mathrm{HCV}$ replication. It would be interesting to test the combined effect of these cytokines on HCV replication in the future.

In conclusion, we showed a set of specific pro-inflammatory cytokine and chemokine proteins induced by $12 \mathrm{e}$ that play an important role in the 12e-dependent anti-HCV activity. Especially, the up-regulation of CXCL-8 protein together with other pro-inflammatory cytokines may play a critical role in suppression of HCV replication by 12e. Based on these results, we anticipate that indole derivatives could be further developed in the near future to serve as a new class of anti-HCV therapeutics with a novel mode of action.

Acknowledgements. This work was supported by the Dongguk University Research Fund 2011.

\section{References}

Blight KJ, McKeating JA, Rice CM (2002): Highly permissive cell lines for subgenomic and genomic hepatitis $C$ virus RNA replication. J. Virol. 76, 13001-13014. http://dx.doi. org/10.1128/JVI.76.24.13001-13014.2002

Casola A, Garofalo RP, Jamaluddin M, Vlahopoulos S, Brasier AR (2000): Requirement of a novel upstream response element in respiratory syncytial virus-induced IL-8 gene expression. J. Immunol. 164, 5944-5951. http://dx.doi. org/10.4049/jimmunol.164.11.5944

Cho NJ, Dvory-Sobol H, Lee C, Cho SJ, Bryson P, Masek M, Elazar M, Frank CW, Glenn JS (2010): Identification of a class of HCV inhibitors directed against the nonstructural protein NS4B. Sci. Transl. Med. 2, 15ra16. http://dx.doi. org/10.1126/scitranslmed.3000331

Choi SC, Choi EJ, Oh HM, Lee S, Lee JK, Lee MS, Shin YI, Choi SJ, Chae JR, Lee KM, Lee WJ, Park JS, Shin CY, Oh TY, Jun CD (2006): DA-9601, a standardized extract of Artemisia asiatica, blocks TNF-alpha-induced IL-8 and CCL20 production by inhibiting p38 kinase and NF-kappaB pathways in human gastric epithelial cells. World J. Gastroenterol. 12, 4850-4858.

Everson GT, Sims KD, Rodriguez-Torres M, Hezode C, Lawitz E, Bourliere M, Loustaud-Ratti V, Rustgi V, Schwartz H, Tatum H, Marcellin P, Pol, S, Thuluvath PJ, Eley T, Wang 
X, Huang SP, McPhee F, Wind-Rotolo M, Chung E, Pasquinelli C, Grasela DM, Gardiner DF (2014): Efficacy of an interferon- and ribavirin-free regimen of daclatasvir, asunaprevir, and BMS-791325 in treatment-naive patients with HCV genotype 1 infection. Gastroenterology 146, 420-429. http://dx.doi.org/10.1053/i.gastro.2013.10.057

Green J, Khabar KS, Koo BC, Williams BR, Polyak SJ (2006): Stability of CXCL-8 and related AU-rich mRNAs in the context of hepatitis C virus replication in vitro. J. Infect. Dis. 193, 802-811. http://dx.doi.org/10.1086/500510

Holtmann H, Winzen R, Holland P, Eickemeier S, Hoffmann E, Wallach D, Malinin NL, Cooper JA, Resch K, Kracht M (1999): Induction of interleukin-8 synthesis integrates effects on transcription and mRNA degradation from at least three different cytokine- or stress-activated signal transduction pathways. Mol. Cell. Biol. 19, 6742-6753.

Jin G, Lee S, Choi M, Son S, Kim GW, Oh JW, Lee C, Lee K (2014): Chemical genetics-based discovery of indole derivatives as HCV NS5B polymerase inhibitors. Eur. J. Med. Chem. 75,: 413-425. http://dx.doi.org/10.1016/j. ejmech.2014.01.062

Koo BC, McPoland P, Wagoner JP, Kane OJ, Lohmann V, Polyak SJ (2006): Relationships between hepatitis C virus replication and CXCL-8 production in vitro. J. Virol. 80, 7885-7893. http://dx.doi.org/10.1128/JVI.00519-06

Lee C (2013a): Daclatasvir: potential role in hepatitis C. Drug Des. Devel. Ther. 7, 1223-1233. http://dx.doi.org/10.2147/ DDDT.S40310

Lee C (2013b): Interaction of hepatitis C virus core protein with Janus kinase is required for efficient production of infectious viruses. Biomol. Ther. (Seoul). 21, 97-106. http:// dx.doi.org/10.4062/biomolther.2013.007

Lindenbach BD, Evans MJ, Syder AJ, Wolk B, Tellinghuisen TL, Liu CC, Maruyama T, Hynes RO, Burton DR, McKeating JA, Rice CM (2005): Complete replication of hepatitis C virus in cell culture. Science 309, 62-626. http://dx.doi. org/10.1126/science. 1114016
Min KN, Joung KE, Kim DK, Sheen YY (2012): Anti-Cancer Effect of IN-2001 in MDA-MB-231 Human Breast Cancer. Biomol. Ther. (Seoul) 20,313-319. http://dx.doi.org/10.4062/ biomolther.2012.20.3.313

Mukherjee S, Sorrell MF (2008): Controversies in liver transplantation for hepatitis C. Gastroenterology 134, 1777-1788. http://dx.doi.org/10.1053/j.gastro.2008.02.035

Shepard CW, Finelli L, Alter MJ (2005): Global epidemiology of hepatitis C virus infection. Lancet Infect. Dis. 5, 558-567. http://dx.doi.org/10.1016/S1473-3099(05)70216-4

Sidwell RW, Huffman JH, Khare GP, Allen LB, Witkowski JT, Robins RK (1972): Broad-spectrum antiviral activity of Virazole: 1-betaD-ribofuranosyl-1,2,4-triazole-3-carboxamide. Science 177, 705-706. http://dx.doi.org/10.1126/science.177.4050.705

Sklan EH, Staschke K, Oakes TM, Elazar M, Winters M, Aroeti B, Danieli T, Glenn JS (2007): A Rab-GAP TBC domain protein binds hepatitis $\mathrm{C}$ virus NS5A and mediates viral replication. J. Virol. 81, 11096-11105. http://dx.doi. org/10.1128/JVI.01249-07

Tokumoto Y, Hiasa Y, Uesugi K, Watanabe T, Mashiba T, Abe M, Kumagi T, Ikeda Y, Matsuura B, Onji M (2012): Ribavirin regulates hepatitis $\mathrm{C}$ virus replication through enhancing interferon-stimulated genes and interleukin 8. J. Infect. Dis. 205, 1121-1130. http://dx.doi.org/10.1093/infdis/jis025

Tscherne DM, Jones CT, Evans MJ, Lindenbach BD, McKeating JA, Rice CM (2006): Time- and temperature-dependent activation of hepatitis $\mathrm{C}$ virus for low-pH-triggered entry. J. Virol. 80, 1734-1741. http://dx.doi.org/10.1128/ JVI.80.4.1734-1741.2006

Van Damme J, Decock B, Conings R, Lenaerts JP, Opdenakker G, Billiau A (1989): The chemotactic activity for granulocytes produced by virally infected fibroblasts is identical to monocyte-derived interleukin 8. Eur. J. Immunol. 19, 1189-1194. http://dx.doi.org/10.1002/eji.1830190706

Wilby KJ, Partovi N, Ford JA, Greanya E, Yoshida EM (2012): Review of boceprevir and telaprevir for the treatment of chronic hepatitis C. Can. J. Gastroenterol. 26, 205-210. 